\title{
Amplification of Growth Regulatory Genes in Intraductal Breast Cancer Is Associated with Higher Nuclear Grade but Not with the Progression to Invasiveness
}

\author{
Sabine Glöckner, Ulrich Lehmann, Nadine Wilke, Wolfram Kleeberger, \\ Florian Länger, and Hans Kreipe \\ Institute of Pathology, Medizinische Hochschule Hannover, Hannover, Germany
}

\begin{abstract}
SUMMARY: Ductal carcinoma in situ (DCIS), as an identifiable progenitor lesion of invasive breast cancer, represents a morphologically, biologically, and prognostically heterogeneous disease. It is not clear which molecular mechanisms are involved in progression to infiltrative growth. In this study, $83 \mathrm{DCIS}$ classified according to the Van Nuys grading scheme were examined for amplification of growth regulatory genes that have been found to be amplified in invasive breast cancer (c-erbB2, topoisomerase $\| / \alpha, c-m y c$, and cyclinD1 genes). Exact quantification of gene amplification was enabled by a combination of laser microdissection of paraffin-embedded tissue with real-time PCR. In DCIS, gene amplifications of all tested genes were found. The most frequently amplified gene was c-erbB2 found in 21 of $83(25 \%)$ cases. Amplification of the other genes under investigation was observed in $4 \%$ to $6 \%$ of cases, high-grade DCIS being predominantly affected. High-grade DCIS differed significantly from low- and intermediate-grade DCIS in frequency and level of c-erbB2 amplification. In addition, high-grade DCIS revealed an accumulation of genetic aberrations. Amplification status in pure in situ lesions did not differ from intraductal carcinoma with an infiltrative component, indicating that although associated with a higher nuclear grade gene amplification might not represent an independent prognostic marker of disease progression. (Lab Invest 2001, 81:565-571).
\end{abstract}

$D$ uctal carcinoma in situ (DCIS) is not a uniform entity, but a heterogeneous disease revealing a spectrum of morphologic differentiations (Tavassoli, 1992). The morphologic heterogeneity may correspond to diverse underlying genetic defects that, however, have not been identified so far (van de Vijver, 1998). Considering the phenotypic diversity, various morphologic classification schemes for DCIS have been proposed as an attempt to estimate its biologic potential as a precursor to invasive carcinoma and to predict the risk of local recurrence after breast conserving therapy (Holland et al, 1994; Silverstein et al, 1995).

A recently proposed grading system, designated the Van Nuys (VN) classification, is a simplified, clinically relevant system defining prognostic groups with differing likelihood of local recurrence after excision (Silverstein et al, 1995). This easily applicable classification facilitates categorization of DCIS by grouping it into three grades based on nuclear size and pleomorphism and the presence or absence of necrosis.

The novel grading schemes of intraductal carcinoma have proven their usefulness in several studies

Received December 22, 2000.

This work was supported by Grant No. DFG Fe 516/1-1.

Address reprint requests to: Dr. Hans Kreipe, Institute of Pathology, Medizinische Hochschule Hannover, Carl-Neuberg-Strasse 1, D-30625 Hannover.E-mail:Kreipe.Hans@MH-Hannover.de
(Silverstein et al, 1995). However they share with histopathologic grading protocols in other organs the difficulties concerning standardization and independence of subjective influences such as the individual experience of the histopathologists (Bethwaite et al, 1998; Sloane et al, 1998). To improve the reproducibility of grading, in particular of borderline cases that are difficult to classify, more must be known about the underlying genetic defects that give rise to the various forms of intraductal carcinoma.

The diversity of genetic alterations found in intraductal and invasive breast cancer so far appears to support the hypothesis of different genetic pathways in the clonal evolution of breast cancer (Buerger et al, 1999a, 1999b). In contrast to epithelia at other sites, where a progression from low through intermediate to severe dysplasia and finally invasive carcinoma is generally accepted, a multistep carcinogenesis model for invasive mammary carcinoma through successive precursor lesions has not yet been proven. Recent studies suggest that the clinical behavior of invasive carcinoma may be determined at a preinvasive stage (Gupta et al, 1997).

Among the different genetic mechanisms acting in carcinogenesis, that is, the activation of oncogenes and the inactivation of suppressor genes, oncogene amplification seems to play an important role, especially in the pathogenesis of invasive breast cancer concerning about 20 amplified chromosome regions in 
comparative genomic hybridization analyses (Courjal et al, 1997; Knuutila et al, 1998). The genes most frequently affected by amplification in breast cancer are the genes for c-erbB2, topoisomerase $\| \alpha$, c-myc, and cyclinD1.

To investigate whether gene amplification is associated with the grading or progression to invasiveness of intraductal carcinoma, we determined the frequency and degree of gene amplification in low- to high-grade DCIS as defined by the VN classification. Laser-based microdissection of paraffin-embedded DCIS specimens was applied to obtain pure tumor cell groups (Lehmann et al, 2000). The subsequent quantitative PCR analysis with the TaqMan detection system (Applied Biosystems, Foster City, California) allowed the objective and reproducible quantification even of low-level amplifications in minute tissue samples (Bieche et al, 1998; Heid et al, 1996). The combination of these two novel technologies provides an excellent tool for studies of genetic alterations in neoplastic preinvasive breast lesions, which are often of limited size or available only in paraffin-embedded tissue (Lehmann et al, 2000).

\section{Results}

\section{Gene Amplifications and DCIS}

The results of the PCR analyses of all DCIS specimens are summarized in Table 1. Among the 83 cases included in this study, 30 (36\%) DCIS specimens displayed gene amplifications.

c-erbB2 amplification was observed in 21 of 83 (25\%) cases, representing the most frequent copy number increase of all oncogenes tested. Six tumors re- vealed low-level amplification (2-fold to $<5$-fold), whereas 11 cases presented intermediate-level amplification ( $\geq 5$-fold to $<10$-fold). The remaining four cases showed high-level c-erbB2 amplifications (up to 25-fold).

Topoisomerase // $\alpha$ amplification was found in 3 of 83 $(4 \%)$ cases. Copy number increase did not exceed 4-fold, corresponding to low-level amplification.

CyclinD1 amplification occurred in 5 (6\%) tumors with a copy number increase ranging from 2-fold to 6-fold, corresponding to low- and intermediatelevel amplification, respectively.

c-myc amplification was exhibited in $5(6 \%)$ cases, with copy number increase ranging from 3-fold to 4-fold.

\section{Gene Amplifications and VN Classification}

DCIS VN1. Eleven cases were classified as lowgrade DCIS, VN1. In this group no copy number aberrations of the tested genes were detected.

DCIS VN2. Twelve cases were classified as VN2. Two of these specimens revealed low-level gene amplifications: in one case c-erbB2 amplification (4-fold) was detected, another case showed c-myc amplification (4-fold).

DCIS VN3. Sixty cases were classified as highgrade DCIS, VN3. Altogether, 28 cases showed copy number increase of the tested genes. The most frequent amplification was c-erbB2 amplification, which was found in $20(33 \%)$ cases. Statistical analysis revealed a highly significant association between high-grade DCIS VN3 and frequency of c-erbB2 amplification by exact linear trend test $(p=0.006)$, as well

Table 1. Frequency of Gene Amplifications in 83 Cases of Ductal Carcinoma In Situ Correlated with Van Nuy's (VN) Grading and the Absence (pTis) or Presence (pT1-pT2) of Invasive Tumor Components

\begin{tabular}{|c|c|c|c|c|c|c|}
\hline & & & $c-e r b B 2$ & topo $/ / \alpha$ & cyclinD1 & $c-m y c$ \\
\hline pTNM & Grading & $n$ & $+/-^{a}$ & $+1-$ & $+/-$ & $+/-$ \\
\hline \multirow[t]{9}{*}{ pTis } & VN1 & 6 & $0 / 6$ & $0 / 6$ & $0 / 6$ & $0 / 6$ \\
\hline & VN2 & 4 & $1 / 3(25 \%)$ & $0 / 4$ & $0 / 4$ & $0 / 4$ \\
\hline & VN3 & 27 & $11 / 16(40 \%)$ & $2 / 25(7 \%)$ & $3 / 24(11 \%)$ & $1 / 26(4 \%)$ \\
\hline & pap & 2 & $0 / 2$ & $0 / 2$ & $0 / 2$ & $0 / 2$ \\
\hline & cribri & 9 & $0 / 9$ & $0 / 9$ & 2/7 (22\%) & $0 / 9$ \\
\hline & тісрар & 2 & $1 / 1$ & $0 / 2$ & $0 / 2$ & $0 / 2$ \\
\hline & solid & 8 & $4 / 4(50 \%)$ & $0 / 8$ & $0 / 8$ & $0 / 8$ \\
\hline & mixed & 9 & $4 / 5(44 \%)$ & $2 / 7(22 \%)$ & $0 / 9$ & $0 / 9$ \\
\hline & comedo & 7 & $3 / 4(33 \%)$ & $0 / 7$ & 1/6 (14\%) & $1 / 6(14 \%)$ \\
\hline \multirow[t]{9}{*}{ pT1-2 } & VN1 & 5 & $0 / 5$ & $0 / 5$ & $0 / 5$ & $0 / 5$ \\
\hline & VN2 & 8 & $0 / 8$ & $0 / 8$ & $0 / 8$ & $1 / 7(12 \%)$ \\
\hline & VN3 & 33 & $9 / 24(27 \%)$ & 1/32 (3\%) & 2/31 (6\%) & $3 / 30(9 \%)$ \\
\hline & рар & 2 & $1 / 1$ & $0 / 2$ & $0 / 2$ & $0 / 2$ \\
\hline & cribri & 5 & $0 / 5$ & $0 / 5$ & $0 / 5$ & $0 / 5$ \\
\hline & тісрар & 1 & $1 / 0$ & $0 / 1$ & $0 / 1$ & $0 / 1$ \\
\hline & solid & 8 & $4 / 4(50 \%)$ & $1 / 7$ (12\%) & 1/7 (12\%) & $1 / 7(12 \%)$ \\
\hline & mixed & 25 & $2 / 23(8 \%)$ & $0 / 25$ & $1 / 24(4 \%)$ & $2 / 23(8 \%)$ \\
\hline & comedo & 5 & $1 / 4(20 \%)$ & $0 / 5$ & $0 / 5$ & $1 / 4(20 \%)$ \\
\hline
\end{tabular}

pap, papillary; cribri, cribriform; micpap, micropapillary; mixed, mixed growth pattern.

$a+/-$, amplified/not amplified. 
as $c$-erbB2 amplification level by Kruskal-Wallis test ( $p$ $=0.02)$.

There were three cases of topoisomerase /l $\alpha$ amplifications. Although in two of these cases, a combined c-erbB2/topoisomerase $/ / \alpha$ coamplification was found, a single case displayed an isolated topoisomerase $/ / \alpha$ copy number increase. In five cases, a copy number increase of the cyclinD1 gene was detected. Four DCIS specimens in this group exhibited c-myc amplification. One case in this group revealed increased copy numbers of three target genes at different loci, that is, amplification of the c-erbB2, c-myc, and cyclinD1 genes. The distribution of gene amplifications exhibited highly significant correlation to grading according to $\mathrm{VN}$ classification by exact linear trend test $(p=0.003)$.

\section{DCIS Associated with Invasive Components vs Pure DCIS}

In contrast to pure intraductal carcinoma (pTis), in which 12 of 37 (32\%) cases exhibited c-erbB2 amplifications, in DCIS associated with an invasive component (pT1-2), 9 of 46 (20\%) cases showed a lower frequency of c-erbB2 amplification. The comparison of these rates reached no statistically significant difference. Accordingly, no significant differences were observed with the other genes under study.

\section{Discussion}

Laser-based microdissection enables molecular studies even on small lesions without contamination by non-neoplastic stroma cells, thus preserving the cytologic and tissue architecture necessary to confirm histopathologic criteria. The subsequent quantitative PCR analysis of the selected cell groups using the TaqMan detection system allows the accurate detection of low-level amplifications even in minute tissue samples (Lehmann et al, 2000).

As target genes we selected four genes found to be frequently amplified in invasive breast cancer (Cuny et al, 2000). c-erbB2 at locus 17q21-22 encodes a membrane-bound tyrosine kinase receptor (Kallioniemi et al, 1992). In proximate vicinity to c-erbB2, the topoisomerase $/ / \alpha$ gene at 17q12-21 encodes a key enzyme in DNA replication (Kreipe et al, 1993b), which is the molecular target for the topoisomerase $1 / \alpha$ inhibitors that represent important anticancer drugs (Jarvinen et al, 2000). The oncogene c-myc at 8q24 is a key regulator of cell cycle progression from $\mathrm{G} 1$ to $\mathrm{S}$ phase (Kreipe et al, 1993a). The cell cycle regulatory gene cyclinD1, sited on locus 11q13, is essential for G1 phase progression and is implicated in the pathogenesis of several human malignancies, including breast cancer (Barnes and Gillett, 1998; Tanner et al, 1998; Vos et al, 1999a).

Investigating the amplification status of these genes in DCIS might elucidate at which stage of evolution of invasive carcinoma these common amplifications occur. Current classifications of DCIS are based on morphologic criteria to define well-, intermediately, and poorly differentiated lesions that have been vali- dated by clinical follow-up and biologic marker studies (Kanthan et al, 2000). Knowledge about molecular alterations in the different types of DCIS so far has been achieved mostly by loss of heterozygosity ( $\mathrm{LOH})$ (Fujii et al, 1996) and comparative genomic hybridization (Buerger et al, 1999a; Kuukasjarvi et al, 1997; Moore et al, 1999) studies as suitable screening methods. These studies detected widespread chromosomal abnormalities, particularly in high-grade DCIS. In contrast, this study focuses on amplification of growth regulatory genes in DCIS and relates them to the grading scheme of the VN classification.

We found that oncogene amplification does occur in DCIS. Consequently, it might represent an early step in tumorigenesis. The most common gene amplification detected concerned $c$-erbB2, which appeared in 21 of the 83 examined cases. These data suggest that c-erbB2 amplification may play an important role in growth factor-independent growth. In keeping with previous studies performed on invasive breast carcinomata (Jarvinen et al, 2000), topoisomerase $/ / \alpha$ amplifications were found mostly combined with c-erbB2 amplifications, which might be attributable to extensive amplicons constitute both neighboring gene loci. The comparably low-frequency of $c-m y c$ amplifications in only $6 \%$ (5 of 83 ) of DCIS specimens compared with results of studies (Kreipe et al, 1993a) performed on invasive carcinoma implies that c-myc amplification might not represent an early genetic alteration in carcinogenesis. Vos and colleagues did not find $c-m y c$ amplification in DCIS by Southern analysis (Vos et al, 1999b), indicating the higher sensitivity of the method used in this study. Considering the almost exclusive occurrence of this oncogene amplification in high-grade DCIS lesions, c-myc amplification might increase cell growth and promote tumor progression in later stages of carcinogenesis. In this study, cyclinD1 amplification was detected in 6\% (5 of 83 ) of the examined cases. Previous studies on DCIS using Southern blot (Vos et al, 1999a) and FISH (Simpson et al, 1997) obtained amplification frequencies of $10 \%$ (3 of 32 ) to $18 \%$ (16 of 88 ), which differ only slightly from our results. Similar to $c-m y c$, the rather low percentage of cyclinD1-amplified cases of DCIS compared with the figures published in invasive tumors (Courjal et al, 1996; Dickson et al, 1995) might be due to a later occurrence during tumor evolution.

The distribution of gene amplifications shows significant differences between the three groups of VN classification. Among the four target genes, the frequency and the level of c-erbB2 amplification differ significantly in Group VN3 compared with low- or intermediate-grade DCIS of groups VN1 and VN2. Moreover, high-grade lesions of Group VN3 show an accumulation of genetic alterations; coamplifications or the combined occurrence of amplifications and deletions at different genes were seen. Our findings, combined with a number of previous studies that used different approaches, particularly comparative genomic hybridization (Buerger et al, 1999a; Kuukasjarvi et al, 1997; Moore et al, 1999), indicate that high-grade DCIS harbors extensive genetic alterations. 

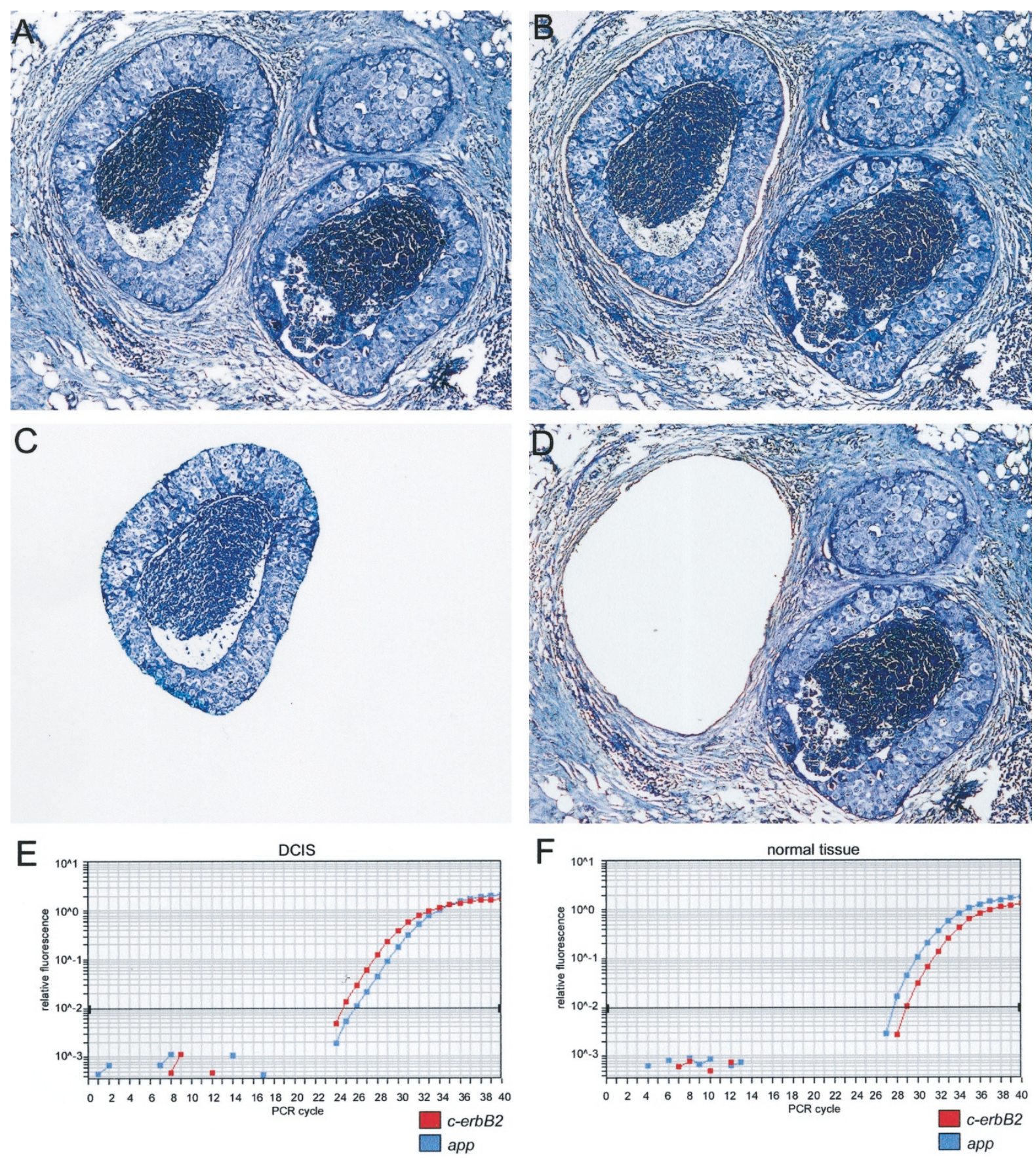

Figure 1.

Laser microdissection and subsequent quantitative PCR analysis of intraductal carcinoma cells (Case 9). A to D, Dissection and isolation of intraductal tumor cells (methylene blue staining, original magnification, $\times 100$ ). $E$ and $F$, Amplification of the $c$-erbB2 gene in DCIS (E) leads to shifting of the amplification plot (red line) to the left compared with adjacent microdissected normal tissue (F) (intermediate level of amplification: $5.2 \pm 0.8$ ). App gene (blue line) serves as internal reference gene.

In conclusion, this study reveals that gene amplifications are present from the early preinvasive stages of breast cancer development and tend to occur in high-grade lesions as classified by the VN grading scheme. When intraductal carcinomata with progression to invasiveness were compared with pure in situ lesions, no significant differences of the amplification status of the genes under study were found. Future studies that directly compare invasive and noninvasive components of breast cancer are required to elucidate whether amplification of $c-m y c$ and cyclinD1 evolve during the progression to invasiveness. Oncogene amplification in intraductal cancer does not appear to be an independent indicator of disease progression.

\section{Materials and Methods}

\section{Patient Material and Histopathologic Diagnosis}

A total of 83 cases of DCIS were retrieved from the surgical pathology files of the archive of the Hannover Medical School. One representative formalin-fixed, 


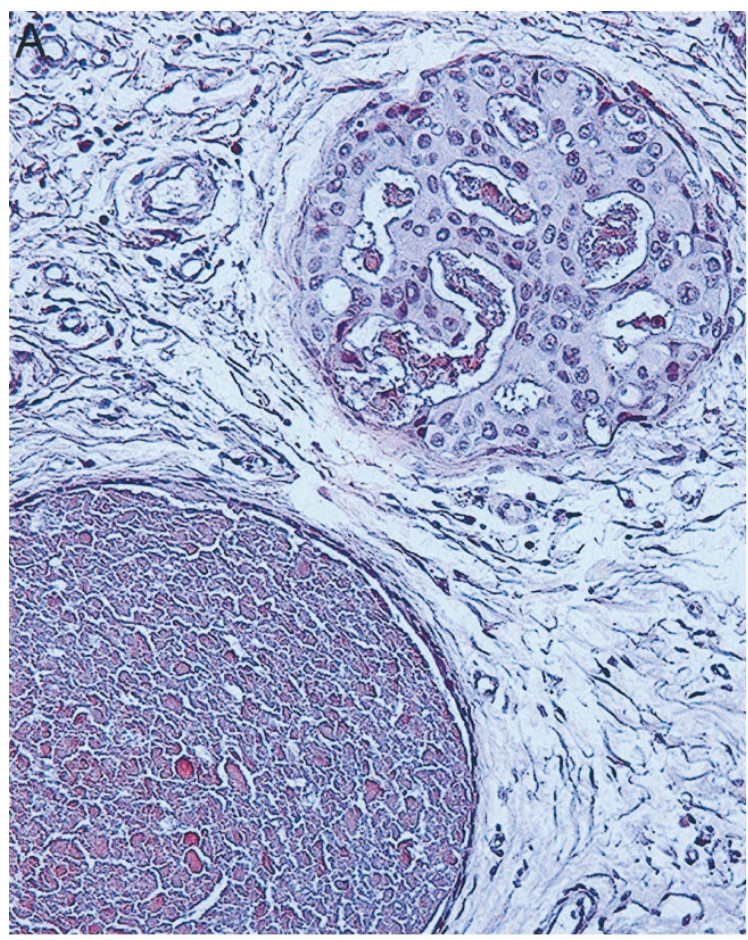

B
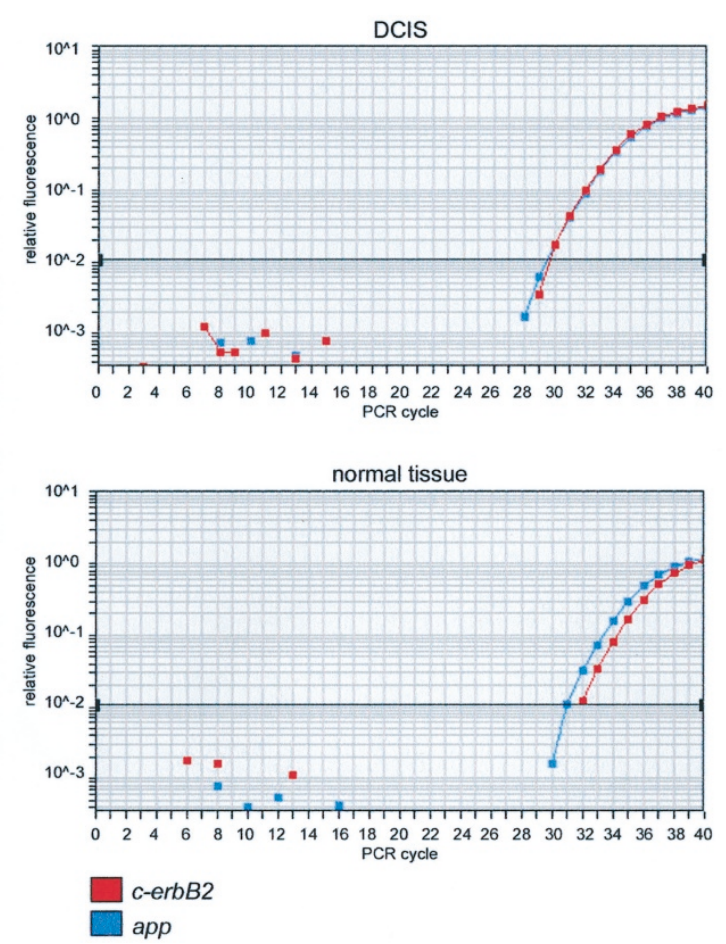
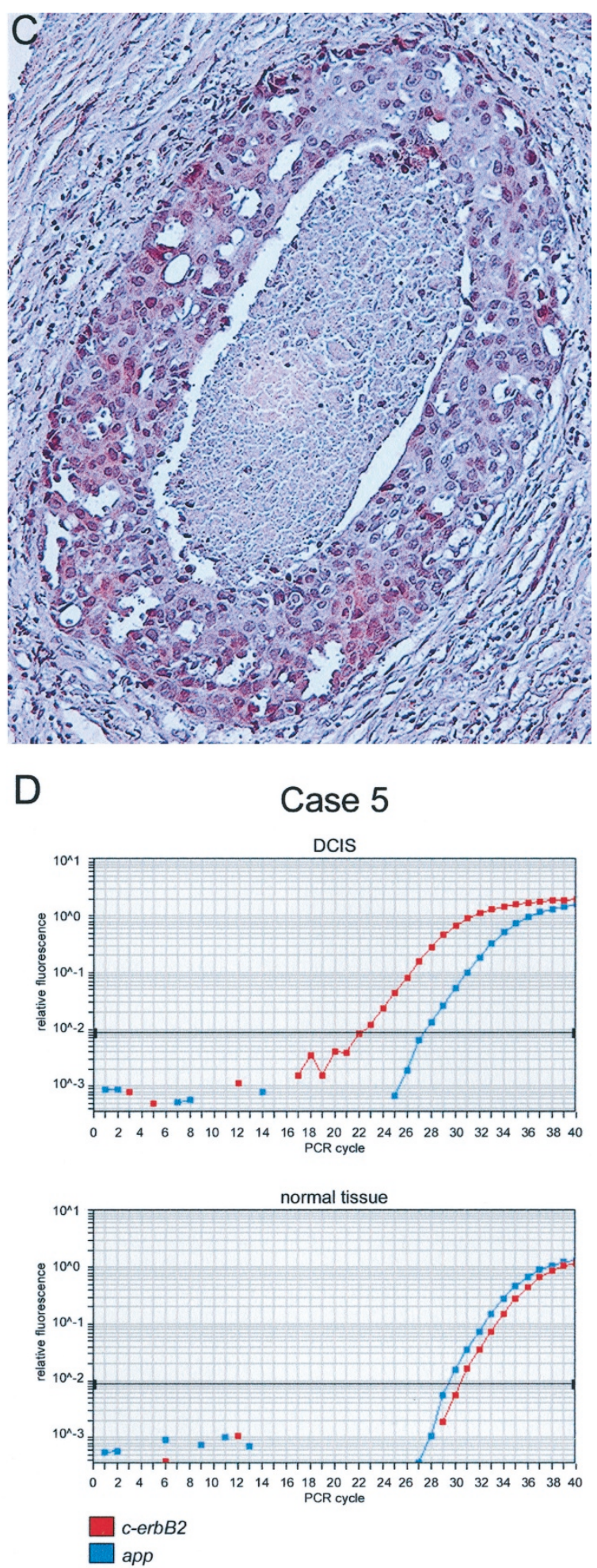

Figure 2.

Quantification of c-erbB2 amplification in two specimens of DCIS VN3. A and C, The histologic appearance (hematoxylin and eosin stained, original magnification $\times 200$ ); and B and D, the corresponding amplification plots. A and B, Low-level amplification in Case 17 with a small shift of the $c$-erbB2 amplification plot (red line) of about one PCR cycle to the left compared with adjacent normal tissue. App gene (blue line) serves as an internal reference gene. $\mathrm{C}$ and D, High-level amplification in Case 5 with a much greater shifting range of the $c$-erbB2 amplification plot of about five PCR cycles to the left. App gene (blue line) serves as an internal reference gene.

paraffin-embedded block was chosen for study from each case after review of hematoxylin and eosin (HE)-stained slides. Thirty-seven cases were diagnosed as pure DCIS without concomitant or subsequent invasive carcinoma development, corresponding to a tumor node metastasis (TNM) stage of pTis. Another 46 cases revealed intraductal and adjacent invasive tumor components, correspond- 
ing to a TNM-stage of pT1-2 (for case selection see Table 1).

According to the three-tiered system of the VN classification (Silverstein et al, 1995), DCIS was categorized into high (VN3), intermediate (VN2), and low grade (VN1). Each case was independently examined by two pathologists ( $\mathrm{HK}$ and $\mathrm{FL}$ ). Conflicting cases with discrepant grades were reviewed and discussed on a multiheaded microscope to achieve consensus. Apart from the evaluation of nuclear grade and the presence or absence of necrosis according to the VN classification, growth pattern and other histologic criteria, and adjacent pathologic lesions, such as proliferating mastopathy, were recorded.

Eleven cases (13\%) were classified as low grade, VN1, 12 cases (14\%) as intermediate grade, VN2, and 60 cases $(72 \%)$ as high grade, VN3 (Table 1$)$.

\section{Microdissection and Real-Time PCR}

Microdissection and real-time PCR were performed essentially as previously described (Bieche et al, 1998; Heid et al, 1996; Lehmann et al, 2000) (Fig. 1).

The primer and probe sequences and the magnesium concentration are as follows (in all cases, the first oligonucleotide is the forward primer, the second is the TaqMan probe, and the third is the reverse $P C R$ primer): c-erbB2: 5'-AGCCTCTGCATTTAGGGATTCTC; 6FAM5'TGAGAACGGCTGCAGGCAACCC-3'TAMRA, and 5'CTAGCGCCGGGACGC (4.5 mmol// $\mathrm{MgCl}_{2}$ ); topoisomerase $\| \alpha:$ 5'-GCCAGAATCTGTTCGCTTCAAC, 6FAM5'AAGCAGCCAGGCTGCCTGTCCAG-3'TAMRA, and 5'AGGAAACTGAGTGCCGGCTT (5 mmol/l $\mathrm{MgCl}_{2}$ ); c-myc: 5'-CCACGTCTCCACACATCAGC, 6FAM5'AACTACGCAGCGCCTCCCTCCAC-3'TAMRA, and 5'TTGGCAGCAGGATAGTCCTTC (6 mmol/l $\left.\mathrm{MgCl}_{2}\right)$; cyclinD1: 5'-GGTCTGTGCATTTCTGGTTGC, 6FAM5'CGGCGCTTCCCAGCACCAA-3'TAMRA, and 5'-GCTGGAAACATGCCGGTTAC (4 mmol/l $\mathrm{MgCl}_{2}$ ); app: 5'TCAGGTTGACGCCGCTGT, 6FAM5'-ACCCCAGAGGAGCGCCACCTG-3'TAMRA, and 5'-TTCGTAGCCGTTCTGCTGC (3.5 mmol// $\left.\mathrm{MgCl}_{2}\right)$.

\section{Evaluation of Results}

The relative gene copy number was evaluated on the basis of the threshold cycles $\left(\mathrm{C}_{\mathrm{T}}\right.$-values) of the gene of interest and of an internal reference gene. The app gene served as an internal reference gene, sited on locus 4q11-q13, for which no amplifications in breast cancer have been reported. By subtraction of the $\mathrm{C}_{\mathrm{T}}$-value of the reference gene from the $\mathrm{C}_{\mathrm{T}}$-values of the test gene in the same tumor sample, the $\Delta \mathrm{C}_{\mathrm{T}[\mathrm{DCIS}]^{-}}$ values for each of the four target genes were determined. These $\Delta \mathrm{C}_{\mathrm{T}[\mathrm{DCIS}]}$-values for each test gene were then compared with a reference range derived from $\Delta \mathrm{C}_{\mathrm{T} \text { [normal tissue] }}$-values. To determine this reference range, normal non-neoplastic tissue samples (mostly stroma cells and lymphocytes) were examined after microdissection from 60 slides of DCIS cases included in this study that had adjacent non-neoplastic tissue on the selected paraffin block.
In consideration of PCR variabilities caused by fixation artifacts or sample impurities, the reference range for each test- or reference-gene pair in normal tissue was determined as follows:

Reference range $=\left[\overline{\mathrm{x}}\left(\Delta \mathrm{C}_{\mathrm{T}[\text { normal tissue }]}\right) \pm \mathrm{SD}\right] \pm 1$, where $\bar{X}$ is mean and $S D$ is standard deviation.

In general, a reduction of the relative $\mathrm{C}_{\mathrm{T}}$-value by one cycle corresponds to a level of amplification of 1.8 \pm 0.1 (Lehmann et al, 2000).

The level of amplification was graded as follows: low-level amplification (copy number increase of 2-fold to $<5$-fold), intermediate-level amplification ( $\geq 5$-fold to $<10$-fold), and high-level amplification ( $\geq 10$-fold) (Fig. 2).

\section{Statistical Analysis}

Statistical analyses for comparing amplification frequency/level and grades according to VN classification, as well as TNM-stage, were performed by linear trend test (exact), Fisher's test (exact), and KruskalWallis test.

\section{References}

Barnes DM, and Gillett CE (1998). Cyclin D1 in breast cancer. Breast Cancer Res Treat 52:1-15.

Bethwaite P, Smith N, Delahunt B, and Kenwright D (1998). Reproducibility of new classification schemes for the pathology of ductal carcinoma in situ of the breast. J Clin Pathol $51: 450-454$.

Bieche I, Olivi M, Champeme MH, Vidaud D, Lidereau R, and Vidaud M (1998). Novel approach to quantitative polymerase chain reaction using real- time detection: Application to the detection of gene amplification in breast cancer. Int $\mathrm{J}$ Cancer 78:661-666.

Buerger H, Otterbach F, Simon R, Poremba C, Diallo R, Decker T, Riethdorf L, Brinkschmidt C, DockhornDworniczak B, and Boecker W (1999a). Comparative genomic hybridization of ductal carcinoma in situ of the breast-evidence of multiple genetic pathways. J Pathol 187: 396-402.

Buerger H, Otterbach F, Simon R, Schafer KL, Poremba C, Diallo R, Brinkschmidt C, Dockhorn-Dworniczak B, and Boecker W (1999b). Different genetic pathways in the evolution of invasive breast cancer are associated with distinct morphological subtypes. J Pathol 189:521-526.

Courjal F, Cuny M, Simony-Lafontaine J, Louason G, Speiser P, Zeillinger R, Rodriguez C, and Theillet C (1997). Mapping of DNA amplifications at 15 chromosomal localizations in 1875 breast tumors: Definition of phenotypic groups. Cancer Res 57:4360-4367.

Courjal F, Louason G, Speiser P, Katsaros D, Zeillinger R, and Theillet $C$ (1996). Cyclin gene amplification and overexpression in breast and ovarian cancers: Evidence for the selection of cyclin D1 in breast and cyclin E in ovarian tumors. Int J Cancer 69:247-253.

Cuny M, Kramar A, Courjal F, Johannsdottir V, lacopetta B, Fontaine H, Grenier J, Culine S, and Theillet C (2000). Relating genotype and phenotype in breast cancer: An analysis of the prognostic significance of amplification at eight different genes or loci and of p53 mutations. Cancer Res 60:1077-1083. 
Dickson C, Fantl V, Gillett C, Brookes S, Bartek J, Smith R, Fisher C, Barnes D, and Peters G (1995). Amplification of chromosome band 11q13 and a role for cyclin D1 in human breast cancer. Cancer Lett 90:43-50.

Fujii H, Szumel R, Marsh C, Zhou W, and Gabrielson E (1996). Genetic progression, histological grade, and allelic loss in ductal carcinoma in situ of the breast. Cancer Res 56:52605265.

Gupta SK, Douglas-Jones AG, Fenn N, Morgan JM, and Mansel RE (1997). The clinical behavior of breast carcinoma is probably determined at the preinvasive stage (ductal carcinoma in situ). Cancer 80:1740-1745.

Heid CA, Stevens J, Livak KJ, and Williams PM (1996). Real time quantitative PCR. Genome Res 6:986-994.

Holland R, Peterse JL, Millis RR, Eusebi V, Faverly D, van de Vijver MJ, and Zafrani B (1994). Ductal carcinoma in situ: A proposal for a new classification. Semin Diagn Pathol 11: $167-180$

Jarvinen TA, Tanner M, Rantanen V, Barlund M, Borg A, Grenman S, and Isola J (2000). Amplification and deletion of topoisomerase Ilalpha associate with erbB-2 amplification and affect sensitivity to topoisomerase II inhibitor doxorubicin in breast cancer. Am J Pathol 156:839-847.

Kallioniemi OP, Kallioniemi A, Kurisu W, Thor A, Chen LC, Smith HS, Waldman FM, Pinkel D, and Gray JW (1992). erbB2 amplification in breast cancer analyzed by fluorescence in situ hybridization. Proc Natl Acad Sci USA 89:53215325.

Kanthan R, Xiang J, and Magliocco AM (2000). p53, ErbB2, and TAG-72 expression in the spectrum of ductal carcinoma in situ of the breast classified by the Van Nuys system. Arch Pathol Lab Med 124:234-239.

Knuutila S, Bjorkqvist AM, Autio K, Tarkkanen M, Wolf M, Monni O, Szymanska J, Larramendy ML, Tapper J, Pere H, El-Rifai W, Hemmer S, Wasenius VM, Vidgren V, and Zhu Y (1998). DNA copy number amplifications in human neoplasms: Review of comparative genomic hybridization studies. Am J Pathol 152:1107-1123.

Kreipe H, Feist H, Fischer L, Felgner J, Heidorn K, Mettler L, and Parwaresch R (1993a). Amplification of $c$-myc but not of $c$-erbB-2 is associated with high proliferative capacity in breast cancer. Cancer Res 53:1956-1961.

Kreipe H, Heidebrecht HJ, Hansen S, Rohlk W, Kubbies M, Wacker $\mathrm{HH}$, Tiemann M, Radzun HJ, and Parwaresch $\mathrm{R}$ (1993b). A new proliferation-associated nuclear antigen detectable in paraffin-embedded tissues by the monoclonal antibody Ki-S1. Am J Pathol 142:3-9.

Kuukasjarvi T, Tanner M, Pennanen S, Karhu R, Kallioniemi OP, and Isola J (1997). Genetic changes in intraductal breast cancer detected by comparative genomic hybridization. Am J Pathol 150:1465-1471.
Lehmann U, Glockner S, Kleeberger W, Feist H, von Wasielewski R, and Kreipe H (2000). Detection of gene amplification in archival breast cancer specimens by laserassisted microdissection and quantitative real-time polymerase chain reaction. Am J Pathol 156:1855-1864.

Moore E, Magee H, Coyne J, Gorey T, and Dervan PA (1999). Widespread chromosomal abnormalities in high-grade ductal carcinoma in situ of the breast: Comparative genomic hybridization study of pure high-grade DCIS. J Pathol 187:403409.

Silverstein MJ, Poller DN, Waisman JR, Colburn WJ, Barth A, Gierson ED, Lewinsky B, Gamagami P, and Slamon DJ (1995). Prognostic classification of breast ductal carcinomain-situ. Lancet 345:1154-1157.

Simpson JF, Quan DE, O'Malley F, Odom-Maryon T, and Clarke PE (1997). Amplification of CCND1 and expression of its protein product, cyclin D1, in ductal carcinoma in situ of the breast. Am J Pathol 151:161-168.

Sloane JP, Amendoeira I, Apostolikas N, Bellocq JP, Bianchi S, Boecker W, Bussolati G, Coleman D, Connolly CE, Dervan $P$, Eusebi V, De Miguel C, Drijkoningen M, Elston CW, Faverley D, Gad A, Jacquemier J, Lacerda M, MartinezPenuela J, Munt C, Peterse JL, Rank F, Sylvan M, Tsakraklides V, and Zafrani B (1998). Consistency achieved by 23 European pathologists in categorizing ductal carcinoma in situ of the breast using five classifications. European Commission Working Group on Breast Screening Pathology. Hum Pathol 29:1056-1062.

Tanner MM, Karhu RA, Nupponen NN, Borg A, Baldetorp B, Pejovic T, Ferno M, Killander D, and Isola JJ (1998). Genetic aberrations in hypodiploid breast cancer: Frequent loss of chromosome 4 and amplification of cyclin D1 oncogene. Am J Pathol 153:191-199.

Tavassoli FA (1992). Intraductal carcinoma. In: Tavassoli FA, editor. Pathology of the breast. Norwalk, Connecticut: Appleton \& Lange, 229-261.

van de Vijver MJ (1998). Ductal carcinoma in situ of the breast: Histological classification and genetic alterations. Recent Results Cancer Res 152:123-134.

Vos CB, Ter Haar NT, Peterse JL, Cornelisse CJ, and van de Vijver MJ (1999a). Cyclin D1 gene amplification and overexpression are present in ductal carcinoma in situ of the breast. J Pathol 187:279-284.

Vos CB, Ter Haar NT, Rosenberg C, Peterse JL, CletonJansen AM, Cornelisse CJ, and van de Vijver MJ (1999b). Genetic alterations on chromosome 16 and 17 are important features of ductal carcinoma in situ of the breast and are associated with histologic type. Br J Cancer 81:1410-1418. 